\title{
Reducing symptoms of major depressive disorder through a systematic training of general emotion regulation skills: protocol of a randomized controlled trial
}

Anna M Ehret ${ }^{1 *}$, Judith Kowalsky ${ }^{1}$, Winfried Rief ${ }^{1}$, Wolfgang Hiller ${ }^{2}$ and Matthias Berking ${ }^{1,3}$

\begin{abstract}
Background: Major Depressive Disorder is one of the most challenging mental health problems of our time. Although effective psychotherapeutic treatments are available, many patients fail to demonstrate clinically significant improvements. Difficulties in emotion regulation have been identified as putative risk and maintaining factors for Major Depressive Disorder. Systematically enhancing adaptive emotion regulation skills should thus help reduce depressive symptom severity. However, at this point, no study has systematically evaluated effects of increasing adaptive emotion regulation skills application on symptoms of Major Depressive Disorder. In the intended study, we aim to evaluate stand-alone effects of a group-based training explicitly and exclusively targeting general emotion regulation skills on depressive symptom severity and assess whether this training augments the outcome of subsequent individual cognitive behavioral therapy for depression.
\end{abstract}

Methods/Design: In the evaluation of the Affect Regulation Training, we will conduct a prospective randomized-controlled trial. Effects of the Affect Regulation Training on depressive symptom severity and outcomes of subsequent individual therapy for depression will be compared with an active, common factor based treatment and a waitlist control condition. The study sample will include 120 outpatients meeting criteria for Major Depressive Disorder. Depressive symptom severity as assessed by the Hamilton Rating Scale will serve as our primary study outcome. Secondary outcomes will include further indicators of mental health and changes in adaptive emotion regulation skills application. All outcomes will be assessed at intake and at 10 points in time over the course of the 15-month study period. Measures will include self-reports, observer ratings, momentary ecological assessments, and will be complemented in subsamples by experimental investigations and the analysis of hair steroids.

Discussion: If findings should support the hypothesis that enhancing regulation skills reduces symptom severity in Major Depressive Disorder, systematic emotion regulation skills training can enhance the efficacy and efficiency of current treatments for this severe and highly prevalent disorder.

Trial registration: This study is registered with ClinicalTrials.gov, number NCT01330485.

Keywords: Emotion regulation, Major depressive disorder, Treatment, Skills training, Randomized controlled trial

\footnotetext{
* Correspondence: anna.ehret@staff.uni-marburg.de

'Department of Clinical Psychology and Psychotherapy, University of

Marburg, Gutenbergstrasse 18, 35032 Marburg, Germany

Full list of author information is available at the end of the article
} 


\section{Background}

Major Depressive Disorder (MDD) is currently one of the most relevant mental health problems for individuals and societies. With life-time prevalence rates greater than 15\% [1] and rates of chronicity around 20\% [2], MDD ranks fourth among all medical and psychiatric disorders when considering disease burden, and worldwide it is the number one cause of disability [3]. Treatments for MDD have been shown to be effective $[2,4,5]$. However, previous outcome studies also indicate that many patients still suffer from residual symptoms [6] and are likely to relapse within two years after treatment [7]. These findings indicate the need to enhance current psychotherapeutic treatments for MDD.

In an attempt to improve upon existing treatments, research has recently focused on deficits in emotion regulation (ER) as risk factors for the development and maintenance of MDD [8-10]. ER refers to implicit or explicit processes involved in attempts to change the quality, the intensity, or the duration of undesired affective states in accordance with situational demands, biological needs, and individual goals [11-13]. Focusing on aspects relevant to clinical utilization, Berking and colleagues [8,14-16] have conceptualized adaptive ER as the situation-dependent interplay of the abilities to (1) become aware of, (2) identify and label, (3) gain proper understanding of, (4) adaptively modify or (5) accept and tolerate affective reactions, (6) approach and confront situations likely to trigger negative affects when necessary to attain personally relevant goals, and (7) provide compassionate self-support in distressing situations. These abilities have been proposed to help maintain a sense of control in distressing situations and thus reduce the risk of depression $[4,14]$. Adaptive ER skills are also believed to help prevent, reduce or shorten the intensity or duration of dysphoric states that have been found to reactivate depressive thinking patterns contributing to the (re-)occurrence of major depressive episodes $[17,18]$.

Consistent with these assumptions, deficits in ER have been linked to depressive and other psychopathological symptoms; successful application of adaptive ER skills was positively related to indicators of mental health $[19,20]$. Longitudinal $[21,22]$ and experimental $[9,23,24]$ studies support deficits in ER as important antecedents of MDD. In treatment outcome studies, interventions that included work on ER deficits were shown to be effective in treatment for MDD, e.g., Dialectical Behavioral Therapy [25-27], Emotion-Focused Therapy [28,29], and Affect Regulation Training (ART) $[8,14,15]$.

Among all treatments targeting ER, ART is likely the only transdiagnostic program that explicitly and exclusively aims to enhance general ER skills in at-risk and clinical populations. Previous studies have shown preliminary support for the efficacy of ART. In police officers, a group that had been shown to display significantly lower levels of adaptive ER competencies than the normal population, ART helped to enhance adaptive ER skills application [30]. In clinical settings, the ART program was evaluated in samples of inpatients. A randomly selected subgroup of patients meeting criteria for any mental disorder was offered to replace part of their regular cognitive behavioral therapy (CBT) with an abbreviated version of ART. Patients in the ART condition displayed significantly greater increases in adaptive ER, greater decreases in MDD and negative affect, and greater increases in positive affect than patients receiving only conventional CBT [19]. In a prospective randomized controlled trial on individuals meeting criteria for MDD [8], patients allocated to a condition in which some CBT sessions were replaced by a short version of ART also showed greater gains in the acquisition of health-relevant ER skills (modification, acceptance and tolerance of undesired emotions as well as effective selfsupport) and greater reductions of depressive symptoms when compared to patients in the regular CBT condition.

Despite these encouraging findings, existing research on ART is limited by a number of factors. First, previous clinical studies used a short version of ART. Second, ART has not yet been compared with an untreated control condition or with a condition that accounts for unspecific therapeutic factors. Third, it has not yet been investigated whether ART would augment the effects of other empiricallyevidenced treatments for MDD (possibly because enhanced ER skills might allow patients to engage more intensely in the therapeutic process, [31]). Finally, in previous study outcomes the effectiveness of ART was exclusively assessed through self-report measures and only at pre- and posttreatment.

In an attempt to clarify whether experimentally enhancing general ER skills reduces depressive symptom severity and whether fostering adaptive ER skills enhances the outcome of subsequent individual CBT for depression (iCBT$\mathrm{D})$, we will evaluate the efficacy of ART in a prospective randomized controlled trial. Stand-alone and augmenting effects of ART will be compared with a waitlist control condition and a condition controlling for active ingredients common to most empirically evidenced treatments. Primary (depressive symptom severity) and secondary outcomes will be assessed at intake and 10 points over the course of the study. Measurements will include self-reports, observer ratings, ecological momentary assessments (EMA) [32] and will include experimental investigations and the analysis of hair steroids in subsamples.

\section{Methods/Design}

The study is designed as a prospective randomized controlled trial in an outpatient setting. Following three sessions with their individual therapists, enrolled patients will be assigned to the ART group, an active common factor- 
based treatment control condition (CFT-C) or a waitlist control group using a computerized randomization tool (randomisation.net). Group therapies will be provided for 18 hours over the course of 8 weeks. Participants in the waiting condition will be offered to participate in ART after completion of the study. Following the group and a 4-week follow-up waiting phase, all participants will receive 16 hours of standardized and manualized iCBT for depression. Individual treatment will be continued beyond the study if necessary. An overview of the study design is illustrated in Figure 1. The study has been approved by the ethical committee of the German Psychological Society and of the University of Marburg. It was registered with ClinicalTrials.gov, number NCT01330485.

\section{Inclusion and exclusion criteria}

Inclusion criteria will include MDD as the primary diagnosis, age 18 or above, and sufficient German language skills. Exclusion criteria will include high risk of suicide, indication of substantial secondary gain (e.g., compensation issues), additional psychotherapeutic treatments, comorbid psychotic, substance-related, bipolar disorders, organic brain or other severe medical disorders, and severe cognitive impairments. Other comorbid disorders, including personality disorders, will be accepted to increase validity of the study.

\section{Recruitment}

Study participants will be recruited at outpatient treatment centers in Marburg, Mainz, and Kassel. Potential participants will be screened on eligibility and provided with study information on the phone. Interested and potentially eligible patients will receive additional written information on the study and be invited to a Structured Clinical Interview for DSM-IV Axis I and II (SCID I, II) in one of the study centers. Patients meeting inclusion criteria and having provided informed consent will be included in the study. Recruitment will be conducted consecutively, that is, 10 to 15 individuals at a time will be enrolled in each cohort.

\section{Interventions}

Interventions will include ART and CFT-C as group interventions and individual CBT for MDD.

\section{Affect Regulation Training (ART)}

ART was developed as an adjunctive or stand-alone transdiagnostic and group-based intervention, explicitly focusing on an increase in adaptive ER in individuals who meet criteria for mental disorders or are at-risk for developing mental health problems. To foster effective ER, ART utilizes elements from various psychotherapeutic approaches as cognitive behavioral therapy [33], dialectical behavioral therapy [27] emotion focused therapy [29], mindfulnessbased interventions [34], neuro-psychotherapeutic translational approaches [35], compassion-based therapy [36,37], problem solving therapies [38], and strength-focused interventions $[39,40]$. At the beginning of the training, participants are provided with information on emotions including biological and psychological origins, functions, risks, and benefits of emotional reactions. Then seven "vicious cycles" based on findings from the affective neurosciences and deemed important in the long-term maintenance of negative affect, are presented. Individuals are taught skills to break these cycles and enhance effective ER. These skills include muscle and breathing relaxation, nonjudgmental emotional awareness, acceptance, and tolerance, compassionate self-support, the identification of causes of emotional reactions, and modification of affective states. In the building of ER skills, special emphasis is placed on the importance of regular training. Additional information on ART is provided in the ART manual [14-16].

\section{Common Factor Treatment-Control (CFT-C)}

CFT-C was established as an active control group to account for unspecific change mechanisms of psychotherapy (i.e., therapeutic alliance, resource activation, problem activation, motivational clarification, and problem solving) $[35,39]$. Following the identification of personally relevant goals and associated motives, acceptance is targeted for

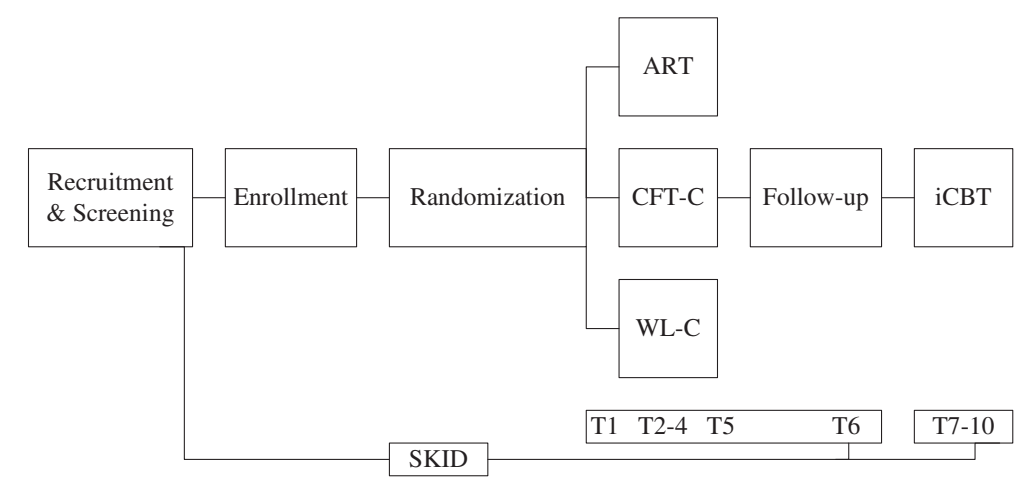

Figure 1 Overview of design and assessments. ART = Affect Regulation Training. CFT =Common Factor-based Treatment. WL $=$ Wait-List. $\mathrm{C}=$ Control Group. iCBT = individual Cognitive Behavioral Therapy. 
goals that cannot or no longer can be achieved; problem solving processes are initiated for achievable goals. Problem solving steps that are taught include the identification and a detailed description of problems and relevant situational features, the definition of goals, the development, evaluation, selection, and processing of solutions, and processes of success monitoring and reinitiating the problem solving or acceptance processes when necessary.

\section{Individual Cognitive Behavioral Therapy for Depression (iCBT-D)}

Individual therapy will cover a 4-month period with 16 (weekly) 50-min sessions in total. Treatment will follow a manualized protocol based on procedures developed by Hautzinger [41], which includes psycho-education on MDD, behavioral activation, cognitive restructuring, social skills training, stress reduction, and relapse prevention.

\section{Assessments}

Participants will be assessed at intake and at 10 points over the course of the study: before (T1), during (T2-4), and after the group-based phase (T5), after the subsequent 4-week follow-up waiting phase before individual CBT starts (T6), during (T7-9), and post the first four months of individual CBT (T10). Measures will include self-report questionnaires, interviews, observer-based ratings, EMA, experimental investigations, and analyses of hair steroids. Questionnaires will all be provided in paper pencil format and in German language. Interviews will be conducted face-to-face by intensively trained Master's students majoring in clinical psychology who will closely be supervised by psychotherapists and psychotherapists in training for CBT, all of whom have Master's degrees in clinical psychology. Participants will be provided with iPhones for the EMA. Over 7-day periods, time-contingent assessments will be taken 3 times per day and one hour after each of the three assessments. Participants will be given the chance to supplement time-contingent assessments with event-contingent assessments whenever they feel significantly distressed. Enrolled patients will also be asked to participate in an experimental investigation of ER skills and to provide hair probes. Participants will be compensated 50 Euros for the burden associated with study diagnostics, and an additional 20 Euros will be provided for participating in the experiment or providing hair probes. An overview of study variables, assessment points, and instruments is provided in Table 1.

\section{Primary outcome}

The level of depressive symptom severity as assessed by the Hamilton Rating Scale for Depression (HRSD) [42] will serve as the primary study outcome. The HRSD is a clinician-administered semi-structured interview that assesses symptoms of MDD. Based on patients' responses, clinicians rate the degree of 24 symptoms such as depressed mood, feelings of guilt, sleeping disturbances, and anxiety on 3-point or 5-point Likert scales. Higher sum scores indicate greater symptom severity. The cut-off points of 10,19, 27, and 35 represent thresholds for mild, moderate, severe, and very severe depression, respectively. The HRSD is sensitive to change and corresponds well with overall clinical ratings of severity $[43,44]$.

\section{Socio-demographic variables}

The following socio-demographic data will be collected: age, gender, marital status, partnership, children, current living situation, educational level, occupation learned, occupation held, and immigration.

\section{Diagnostics}

The Structured Clinical Interviews for DSM-IV Axis I and II (SCID I, II) [45] will be used to assess MDD and comorbid disorders. The SCID is a structured interview that assesses psychiatric diagnosis defined in the Diagnostic and Statistical Manual of the American Psychiatric Association, 4th edition (DSM-IV). The SCID II includes a screening questionnaire to limit the number of questions of the subsequent interview. DSM-5 diagnosis for MDD will be added when possible.

\section{Stressors}

The List of Situational Stressors (LSS) will assess for potential cues of negative emotional reactions to 11 daily events. Individuals are asked to rate how often within the last week they experienced stressors such as arguments with a friend, romantic partner or family member (interpersonal domain), high workload (work-related), financial problems (financial domain), and trouble with means of transport (everyday stressors). The scale has previously been used in a study on affective reactivity as a predictor of depressive symptoms [46].

\section{Additional indicators of mental health}

The Beck Depression Inventory II (BDI II) [47] will be included in this study as a secondary measure of depressive symptom severity. The BDI II is a widely used 21 -item self-report measure of somatic, behavioral, emotional, and cognitive signs of depression. Good reliability and validity have previously been demonstrated [48].

An unpublished German translation of the Scales of Psychological Well-Being (SPWB) [49] will be used as an indicator of psychological well-being. The SPWB includes scales for autonomy, environmental mastery, personal growth, positive relations with others, purpose in life, and self-acceptance. Given that psychometric analyses of the SPWB have not always supported the proposed six factor structure [50,51], we will use the total score in this study. High internal consistency and 
Table 1 Overview of study variables and instruments

\begin{tabular}{|c|c|c|c|c|c|c|c|c|c|c|c|c|}
\hline Domain & Instrument & T0 & $\mathrm{T} 1$ & T2 & T3 & T4 & T5 & T6 & T7 & T8 & T9 & $\mathrm{T} 10$ \\
\hline $\begin{array}{l}\text { Depressive symptom severity } \\
\text { (primary outcome) }\end{array}$ & Hamilton rating scale for depression & & $\times$ & & $x$ & & & $\times$ & & & & $x$ \\
\hline Diagnostics & Structured clinical interview for DSM-IV Axis I, II & $\times$ & & & & & & $\times$ & & & & $x$ \\
\hline Stressors & List of situational stressors & & $\times$ & $\times$ & $x$ & $\times$ & $\times$ & $\times$ & $\times$ & $\times$ & $\times$ & $x$ \\
\hline \multirow[t]{7}{*}{ Additional indicators of mental health } & Beck depression inventory $\|$ & & $\times$ & $\times$ & $x$ & $\times$ & $\times$ & $\times$ & $\times$ & $\times$ & $\times$ & $x$ \\
\hline & Scales of psychological well-being & & $\times$ & $\times$ & $\times$ & $\times$ & $\times$ & $x$ & $\times$ & $\times$ & $\times$ & $x$ \\
\hline & Pos. and neg. affect schedule & & $\times$ & $x$ & $x$ & $\times$ & $\times$ & $x$ & $\times$ & $\times$ & $\times$ & $x$ \\
\hline & Short scales of affective states relevant for psychotherapy & & $\times$ & $\times$ & $\times$ & $\times$ & $\times$ & $\times$ & $\times$ & $\times$ & $\times$ & $\times$ \\
\hline & SHARP/others & & $\times$ & & & & $\times$ & $\times$ & & & & $x$ \\
\hline & Brief symptom inventory & & $\times$ & & & & $\times$ & $\times$ & & & & $x$ \\
\hline & Depression anxiety and stress scale & & $\times$ & $x$ & $x$ & $\times$ & $\times$ & $\times$ & $\times$ & $\times$ & $\times$ & $x$ \\
\hline \multirow[t]{7}{*}{ Emotion regulation } & Emotion reg. skills questionnaire & & $\times$ & $x$ & $\times$ & $\times$ & $\times$ & $\times$ & $\times$ & $\times$ & $\times$ & $x$ \\
\hline & ERSQ- others & & $\times$ & & & & $\times$ & $\times$ & & & & $x$ \\
\hline & Emotion reg. skills questionnaire- emotion specific & & $\times$ & $\times$ & $x$ & $\times$ & $\times$ & $\times$ & $\times$ & $\times$ & $\times$ & $x$ \\
\hline & ERSQ-ES- others & & $\times$ & & & & $\times$ & $\times$ & & & & $x$ \\
\hline & Difficulties in emotion reg. scale & & $\times$ & & & & $\times$ & $\times$ & & & & $x$ \\
\hline & Negative mood regulation scale & & $\times$ & & & & & & & & & \\
\hline & Trait meta-mood scale & & $\times$ & & & & & & & & & \\
\hline \multirow[t]{3}{*}{ Confounding variables } & Self-efficacy scale & & $\times$ & & & & $\times$ & $\times$ & & & & $x$ \\
\hline & Multidim. perfectionism scale & & $\times$ & & & & $\times$ & $\times$ & & & & $x$ \\
\hline & Rosenberg self-esteem scale & & $\times$ & & & & $\times$ & $\times$ & & & & $x$ \\
\hline \multirow[t]{3}{*}{ Additional assessments } & Ecological momentary assessment & & $\times$ & & & & $\times$ & & & & & \\
\hline & Laboratory experiment & & $\times$ & & & & $\times$ & & & & & \\
\hline & Hair steroids & & $\times$ & & & & $\times$ & & & & & $x$ \\
\hline
\end{tabular}

test-retest reliability coefficients were reported in the original validation study [49].

Positive and negative affective states will be assessed using the Positive and Negative Affect Schedule (PANAS) [52]. On 5-point Likert scales $(0=$ not at all to $4=$ almost always), participants are asked to rate the frequency of 20 affective states. Within a previous validation study [52], good internal consistency was revealed, and associations with related constructs such as anxiety, depression, and neuroticism were significant and in the expected directions. To assess more specific emotional reactions, Berking developed the Short Scales for the Assessment of Affective States Relevant in Psychotherapeutic Treatments- Self/ Other (SHARP). On 4-point Likert scales, participants rate how often they experienced 50 different emotions in the past week.

To obtain continuous information on comorbid symptom severity, a global severity index will be computed on all but the depression scales of the Brief Symptom Inventory (BSI) [53]. The BSI is a screening tool for psychological disturbance including depression, somatization, obsessive-compulsive symptoms, interpersonal sensitivity, anxiety, hostility, phobic anxiety, paranoid ideation, and psychoticism. Adequate psychometric properties with very high internal consistency for the total score have previously been reported for the German scale [54]. Accounting for high comorbidity between MDD and anxiety disorders [55], the Depression Anxiety and Stress Scale (DASS-21) [56] will also be administered. The DASS is a 42-item self-report instrument designed to measure the three related negative emotional states of depression, anxiety and stress. To our knowledge, no validation study of the German DASS has been published to date. For the English scale, good to excellent internal consistency scores were reported, and associations with other measures of depression, anxiety, and stress were within the high range [57].

\section{Emotion regulation}

Successful application of adaptive ER skills will be assessed through self-reports and observer-based ratings using the Emotion Regulation Skills QuestionnaireSelf/Other (ERSQ) [20]. The ERSQ is a 27-item measure addressing the application of nine competencies included in the ART model of effective ER (i.e., Awareness, Modification, Acceptance, Understanding, Sensations, Clarity, 
Self-Support, Readiness to Confront, and Tolerance). Results from validation studies [20] indicate that both the total score and the subscales of the ERSQ have good internal consistencies and adequate retest-reliability. Associations with other scales supported the scale's convergent and discriminant validity [20]. To assess ER with regard to specific affective states, the Emotion Regulation Skills Questionnaire- Emotion Specific-Self/Other (ERSQ-ES) [58] will be used. Sound psychometric properties have previously been reported for this scale. The observer-based versions of the ERSQ and ERSQ-ES were developed for the purpose of this study and will be evaluated on the basis of study data.

Further applied ER scales with established psychometric properties include a German translation of the Difficulties in Emotion Regulation Scale (DERS) [59], the Negative Mood Regulation Scale (NMR) [60], and the Trait Meta-Mood Scale (TMMS) [61]. The DERS assesses difficulties in emotional awareness, emotional acceptance, goal-directed behaviors and the application of effective ER strategies. The NMR was designed as a measure of individuals' general expectancies that emotional states can effectively be changed through ways of behaving or thinking. The TMMS is a measure of emotional intelligence including the components of emotional attention, clarity, and mood repair.

\section{Confounding variables}

To control for potential confounds, we will assess general self-efficacy with a 10-item, validated German scale (Skala zur Allgemeinen Selbstwirksamkeitserwartung, ASE) [62]. Perfectionism will be assessed by the Multidimensional Perfectionism Scale (MPS) [63], including 35 items on concerns about mistakes, personal standards, parental expectations, parental criticism, doubts about actions, and organization. The Rosenberg Self-Esteem scale (RSE) [64] will be used as a measure of self-esteem. Adequate psychometric properties of these scales have been reported in the cited studies.

\section{Other outcome measures}

Targeting the issue of cognitive distortion and to increase ecological validity, EMA will be implemented as a real-time assessment of ER, affective states, and affective changes. Within EMA, affective states and ER will be assessed by short scales of the SHARP and ERSQ-ES. Additional questions will address location, activity, and interaction partners. To reduce self-report biases and to yield further information on causality, the effects of adaptive ER on positive and negative affect will be tested experimentally. In laboratory settings, negative and positive affective states will be induced by music and selfrelated statements using the Velten [65] method. Participants will be provided with oral instructions of adaptive
ER strategies (i.e., acceptance, positive reappraisal, compassionate self-support, positive appreciation). Hair probes will be taken to gather data for biological features of MDD. Elevated levels of hair steroids (i.e., cortisol and cortisone) have frequently been linked to MDD [66]. In the analyses of hair steroids, we will use liquid chromatography with linked tandem mass spectrometry.

\section{Participants}

Sample size for the group phase was set to $N=120(n=40$ per condition). A minimum of $n=90$ individuals ( $n=30$ per condition) is expected to complete individual CBT. Targeted sample sizes are based on power calculations. The intended sample of 120 individuals can be expected to provide sufficient power to detect small effects [67].

\section{Statistical analyses}

Data will be analyzed according to intent to treat and treatment completers principles. The intent to treatment analyses will be the primary level of analyses. Mixed effect modeling will serve as the main approach in the analyses of study data and in the treatment of missing values.

Growth curves of ER and depressive symptom severity will be computed per group on the basis of assessments before (T1-T5) and during individual CBT (T6-T10) to test for stand-alone and augmentation effects of ART. Slopes for the ART condition are hypothesized to be larger than those for the active or waitlist control groups, indicating the effectiveness of adaptive ER skills application enhancement and a decrease in depressive symptom severity by the ART program. In the secondary analyses, we will test for ART effects on well-being, positive, and negative affect. Bootstrapping enhanced, multilevel mediation analyses [68] will be conducted to test ER as a mediator of health improvements in the ART condition. Analyses will be conducted computing a total score of adaptive ER and separately for the different ART skills to understand the importance of specific ER skills. Moderated mediation analyses [69] will be used to examine the importance of specific ER skills in the mediation of positive health outcomes. Latent growth curve and latent change score modeling [70] will further be used in the investigation of reciprocal associations between levels and changes of ER and health outcomes. Comorbid symptom severity and potential confounding variables (i.e., general self-efficacy, perfectionism, and self-esteem) will be included in the analyses as moderating variables. The analyses of EMA and the experimental and biological data will serve to increase the validity of the ART evaluation. SEM-based Multi-Trait, Multi-Method approaches will be applied in the investigation of psychometric properties and in the comparison of outcomes by different assessment methods. 


\section{Discussion}

We should find support for our hypothesis that systematically enhancing general ER skills helps reduce depressive symptoms in individuals meeting criteria for MDD, given that deficits in ER are commonly considered a relevant risk and maintaining factor for this disorder. Former studies on ART, a program explicitly and exclusively focusing on an increase in adaptive ER skills application, have provided preliminary support for this assumption $[8,19]$. However, the validity of these studies has been compromised through a number of limitations such as the lack of an untreated control condition or a condition that controls for unspecific therapeutic factors, the lack of testing for augmentation effects of the ART on other treatments such as individual CBT for depression, and the exclusive use of self-reports at pre- and post-treatment. To improve on these limitations of previous studies and to advance the literature on associations between ER and MDD, we will systematically evaluate ART in a prospective randomized controlled trial.

This study will provide significant contributions to the literature. First, by controlling for time and unspecific treatment effects, the results will provide insight into the effects of enhancing the application of adaptive ER skills on symptoms of MDD. Second, from the two-phase design of this study that includes a period of individual CBT following the group phase, the standalone effects of ART on ER and depressive symptom severity can be tested, as well as the augmentation effects of ART on CBT outcomes. Third, the application of various measures, including self-reports, observerbased ratings, momentary assessments, experimental investigations, and the analysis of hair probes, will augment the reliability of findings and help to overcome methodological restrictions such as cognitive distortion and social desirability in retrospective testing and self-reports. The implementation of various assessment points over the course of the study will allow for detailed analyses of changes in and associations between ER and depressive symptom severity.

In light of the methodological strengths, the present study has the potential to substantially increase knowledge on ER processes that underlie and maintain MDD. Given the likely importance of deficits in ER across disorders, this study might also yield a better understanding of comorbidity in MDD, which currently is one of the major challenges in the treatment of depressive disorders. Therapeutically, fostering adaptive ER skills application by ART might substantially improve treatment outcomes for individuals with depressive and possibly also comorbid disorders.

\section{Competing interests}

The authors declare that they have no competing interests.

\section{Authors' contributions}

All authors have made substantial contributions to the conception and execution of the study. The Affect Regulation Training was developed by MB. $M B, W H$ and $W R$ were responsible for acquiring funding for the study. AME, $J K, W R$, and MB will be conducting the study in Marburg, WH and MB will supervise the study in Mainz, and the study will be supervised by MB in Kassel. AME and MB drafted the manuscript. All authors revised it critically and have given final approval for the version to be published.

\section{Acknowledgements}

The study is funded by the German Research Foundation (DFG; numbers BE 4510/3-1 and BE4510/3-2; HI 456/6-2). In addition, the Aus- und Weiterbildung in Klinischer Verhaltenstherapie (AWKV) and the Philipps-University Marburg support the study through research grants to PhD students who will be involved in the study. In addition to the first and second author of this manuscript, the following doctoral students will substantially contribute to the study: Yasemin Cal (Marburg), Marta Filipek (Marburg), Alice Diedrich (Mainz), Michaela Grant (Mainz), Mareike Kirchner (Mainz), Anna Radkovsky (Kassel), Carolin M. Wirtz (Kassel). In addition, several student research assistants will be involved in the collection of study data: Johanna Berwanger, Tamara Beyer, Tanja Doerfler, Sarah Ebinger, Anette Ehlenz, Anne Etzelmueller, Christina Fackiner, Bettina Glombik, Regina Hoefer, Hanna Kadel, Tobias Kube, Marie-Luise Mueller, Caroline Reiter, Anna Uelner, Marvin Ruppert, Jeanine Schwarz, Ragna Zehnder.

\section{Author details}

${ }^{1}$ Department of Clinical Psychology and Psychotherapy, University of Marburg, Gutenbergstrasse 18, 35032 Marburg, Germany. ${ }^{2}$ Department of Clinical Psychology and Psychotherapy, University of Mainz, Wallstraße 3, 55122 Mainz, Germany. ${ }^{3}$ Division Health Trainings Online, Leuphana University Lueneburg, Innovation Incubator, Rotenbleicher Weg 67, 21335 Lueneburg, Germany.

Received: 16 December 2013 Accepted: 2 January 2014 Published: 27 January 2014

\section{References}

1. Kessler RC, Berglund P, Demler O, Jin R, Merikangas KR, Walters EE: Lifetime prevalence and age-of-onset distributions of DSM-IV disorders in the National Comorbidity Survey Replication. Arch Gen Psychiatry 2005, 62(6):593-602.

2. Arnow BA, Constantino MJ: Effectiveness of psychotherapy and combination treatment for chronic depression. J Clin Psychol 2003, 59(8):893-905.

3. Ustün TB, Ayuso-Mateos JL, Chatterji S, Mathers C, Murray CJ: Global burden of depressive disorders in the year 2000. Br J Psychiatry 2004, 184:386-392.

4. Cuijpers P, Berking M, Andersson G, Quigley L, Kleiboer A, Dobson KS: A meta-analysis of cognitive-behavioural therapy for adult depression, alone and in comparison with other treatments. Can J Psychiatry 2013, 58(7):376-385.

5. Hollon SD, Ponniah K: A review of empirically supported psychological therapies for mood disorders in adults. Depress Anxiety 2010, 27(10):891-932.

6. Judd LL, Akiskal HA, Maser JD, Zeller PJ, Endicott J, Coryell W, Paulus MP, Kunovac JL, Leon AC, Mueller TI, Rice JA, Keller MB: A prospective 12-year study of subsyndromal and syndromal depressive symptoms in unipolar major depressive disorders. Arch Gen Psychiatry 1998, 55(8):694-700.

7. Vittengl JR, Clark LA, Dunn TW, Jarrett RB: Reducing relapse and recurrence in unipolar depression: a comparative meta-analysis of cognitive-behavioral therapy's effects. J Consult Clin Psychol 2007, 75(3):475-488

8. Berking M, Ebert D, Cuijpers P, Hofmann SG: Emotion regulation skills training enhances the efficacy of inpatient cognitive behavioral therapy for major depressive disorder: a randomized controlled trial. Psychother Psychosom 2013, 82(4):234-245.

9. Campbell-Sills L, Barlow DH, Brown TA, Hofmann SG: Effects of suppression and acceptance on emotional responses of individuals with anxiety and mood disorders. Behav Res Ther 2006, 44(9):1251-1263.

10. Hofmann SG, Sawyer AT, Witt AA, Oh D: The effect of mindfulness-based therapy on anxiety and depression: a meta-analytic review. J Consult Clin Psychol 2010, 78(2):169-183.

11. Thompson RA: Emotion regulation: $A$ theme in search of definition. Monogr Soc Res Child Dev 1994, 59(2-3):25-52. 
12. Cole PM, Martin SE, Dennis TA: Emotion regulation as a scientific construct: methodological challenges and directions for child development research. Child Dev 2004, 75(2):317-333.

13. Gratz KL, Roemer $\mathrm{L}$ : Multidimensional assessment of emotion regulation and dysregulation: Development, factor structure, and initial validation of the Difficulties in Emotion Regulation Scale. J Psychopathol Behav Assess 2004, 26(1):41-54.

14. Berking M: Training Emotionaler Kompetenzen (Affect regulation training). Heidelberg, Germany: Springer; 2010.

15. Berking M, Whitley B: Affect Regulation Training. New York, NY: Springer. in press.

16. Berking M, Schwarz J: The Affect Regulation Training. In Handbook of Emotion Regulation. Edited by Gross JJ. New York, NY: Guilford Press; 2013:529-547.

17. Jarrett RB, Minhajuddin A, Borman PD, Dunlap L, Segal ZV, Kidner CL, Friedman ES, Thase ME: Cognitive reactivity, dysfunctional attitudes, and depressive relapse and recurrence in cognitive therapy responders. Behav Res Ther 2012, 50(5):280-286.

18. Segal ZV, Kennedy S, Gemar M, Hood K, Pedersen R, Buis T: Cognitive reactivity to sad mood provocation and the prediction of depressive relapse. Arch Gen Psychiatry 2006, 63(7):749-755.

19. Berking M, Wupperman $P$, Reichardt A, Pejic T, Dippel A, Znoj H: Emotionregulation skills as a treatment target in psychotherapy. Behav Res Ther 2008, 46(11):1230-1237.

20. Berking M, Znoj H: Entwicklung und Validierung eines Fragebogens zur standardisierten Selbsteinschaetzung emotionaler Kompetenzen (SEK-27) [Development and validation of the Emotion Regulation Skill Questionnaire (ERSQ-27)]. Zeitschrift fuer Psychiatrie, Psychologie und Psychotherapie 2008, 56(2):141-153.

21. Fehlinger T, Stumpenhorst M, Stenzel N, Rief W: Emotion regulation is the essential skill for improving depressive symptoms. J Affect Disord 2013, 144(1-2):116-122.

22. Radkovsky A, McArdle J, Bockting C, Berking M: Emotion regulation skills predict subsequent reduction of symptom severity during treatment of major depressive disorder. J Consult Clin Psychol. in press.

23. Campbell-Sills L, Barlow DH, Brown TA, Hofmann SG: Acceptability and suppression of negative emotion in anxiety and mood disorders. Emotion 2006, 6(4):587-595.

24. Ehring T, Tuschen-Caffier B, Schnülle J, Fischer S, Gross JJ: Emotion regulation and vulnerability to depression: spontaneous versus instructed use of emotion suppression and reappraisal. Emotion 2010, 10(4):563-572.

25. Harley R, Sprich S, Safren S, Jacobo M, Fava M: Adaptation of dialectical behavior therapy skills training group for treatment-resistant depression. J Nerv Ment Dis 2008, 196(2):136-143.

26. Lynch TR, Morse JQ, Mendelson T, Robins CJ: Dialectical behavior therapy for depressed older adults: a randomized pilot study. Am J Geriatr Psychiatry 2003, 11(1):33-45.

27. Linehan MM: Cognitive-behavioral treatment of borderline personality disorder. New York, NY: Guilford Press; 1993.

28. Ellison JA, Greenberg LS, Goldman RN, Angus L: Maintenance of gains following experiential therapies for depression. J Consult Clin Psychol 2009, 77(1):103-112

29. Greenberg LS: Emotion-focused therapy: coaching clients to work through their feelings. Washington, DC: American Psychological Association; 2002.

30. Berking $M$, Meier C, Wupperman P: Enhancing emotion-regulation skills in police officers: results of a pilot controlled study. Behav Ther 2010, 41(3):329-339.

31. Cloitre $M$, Koenen $\mathrm{KC}$, Cohen $\mathrm{LR}$, Han $\mathrm{H}$ : Skills training in affective and interpersonal regulation followed by exposure: a phase-based treatment for PTSD related to childhood abuse. J Consult Clin Psychol 2002, 70(5):1067-1074.

32. Shiffman S, Stone AA, Hufford MR: Ecological momentary assessment. Annu Rev Clin Psychol 2008, 4:1-32.

33. Beck JS: Cognitive therapy: Basics and beyond. New York, NY: Guilford Press; 1995

34. Kabat Zinn J: Mindfulness-based interventions in context: Past, present, and future [Commentary]. Clin Psychol Sci Pract 2003, 10(2):144-156.

35. Grawe K: Neuropsychotherapy. New York, NY: Psychology Press; 2006.

36. Gilbert P: Compassion focused therapy: The distinctive features. London: Routledge; 2011.

37. Weissman S, Weissman R: Meditation, compassion \& lovingkindness. An approach to vipassana practice. York Beach: Weiser; 1996.

38. D'Zurilla TJ, Nezu AM: Problem-solving therapy. In Handbook of cognitive behavioral therapies. Edited by Dobson KS. New York, NY: Guilford Press; 2010

39. Grawe K: Psychological Therapy. Cambridge, MA: Hogrefe \& Huber; 2002.
40. Duckworth AL, Steen TA, Seligman MEP: Positive psychology in clinical practice. Annu Rev Clin Psychol 2005, 1:629-651.

41. Hautzinger M: Kognitive Verhaltenstherapie bei Depressionen: Behandlungsanleitungen und Materialien. Weinheim, Basel, Berlin: Beltz; 2003.

42. Hamilton M: A rating scale for depression. J Neurol Neurosurg Psychiatry 1960, 23:56-62.

43. Riedel M, Möller HJ, Obermeier M, Schennach-Wolff R, Bauer M, Adli M, Kronmüller K, Nickel T, Brieger P, Lauy G, Bender W, Heuser I, Zeiler J, Gaebelk W, Seemüller F: Response and remission criteria in major depression-a validation of current practice. J Psychiatr Res 2010, 44(15):1063-1068

44. Knesevich JW, Biggs JT, Clayton PJ, Ziegler VE: Validity of the Hamilton Rating Scale for depression. Br J Psychiatry 1977, 131:49-52.

45. Wittchen H-U, Zaudig M, Fydrich T: SKID-I/II Strukturiertes Klinisches Interview für DSM-IV. Deutsche Version. Weinheim: Beltz; 1997.

46. Cohen LH, Gunthert KC, Butler AC, O'Neill SC, Tolpin LH: Daily affective reactivity as a prospective predictor of depressive symptoms. J Pers 2005, 73(6):1687-1713.

47. Hautzinger M, Keller F, Kühner C: Das Beck Depressionsinventar II. Deutsche Bearbeitung und Handbuch zum BDI II. Frankfurt: Harcourt Test Services; 2006.

48. Kühner C, Bürger C, Keller F, Hautzinger M: Reliabilität und Validität des revidierten Beck-Depressions-Inventars (BDI-II) Befunde aus deutschsprachigen Stichproben [Reliability and validity of the revised Beck Depression Inventory (BDI-II). Results from German samples]. Nervenarzt 2006, 78:651-656.

49. Ryff CD: Happiness is everything, or is it? Explorations on the meaning of psychological well-being. J Pers Soc Psychol 1989, 57(6):1069-1081.

50. Springer KW, Hauser RM: An assessment of the construct validity of Ryff's Scales of Psychological Well-Being: Method, mode, and measurement effects. Soc Sci Res 2006, 35:1080-1102.

51. Kafka GJ, Kozma A: The construct validity of Ryff's Scales of Psychological Well-Being (SPWB) and their relationship to measures of subjective well-being. Soc Indic Res 2002, 57(2):171-190.

52. Krohne HW, Egloff B, Kohlmann CW, Tausch A: Untersuchungen mit einer deutschen Version der Positive and Negative Affect Schedule (PANAS). Diagnostica 1996, 42(2):139-156.

53. Franke GH: BSI. Brief Symptom Inventory- Deutsche Version. Manual. Göttingen: Beltz; 2000

54. Geisheim C, Hahlweg K, Fiegenbaum W, Frank M, Schröder B, von Witzleben I: Das Brief Symptom Inventory (BSI) als Instrument zur Qualitätssicherung in der Psychotherapie. Diagnostica 2002, 48(1):28-36.

55. Lamers F, van Oppen $\mathrm{P}$, Comijs HC, Smit JH, Spinhoven $\mathrm{P}$, van Balkom AJ, Nolen WA, Zitman FG, Beekman AT, Penninx BW: Comorbidity patterns of anxiety and depressive disorders in a large cohort study: the Netherlands Study of Depression and Anxiety (NESDA). J Clin Psychiatry 2011, 72(3):341-348.

56. Malcher F: Psychometric properties of the German Depression Anxiety Stress Scales (DASS-21) and the Obsessive-Compulsive-Inventory-Revised (OCI-R): A cross-cultural validation-study. Germany: University of Dresden; 2007.

57. Lovibond PF, Lovibond SH: The structure of negative emotional states: comparison of the Depression Anxiety Stress Scales (DASS) with the Beck Depression and Anxiety Inventories. Behav Res Ther 1995, 33(3):335-343.

58. Ebert DD, Christ O, Berking M: Entwicklung und Validierung eines Fragebogens zur emotionsspezifischen Selbsteinschätzung emotionaler Kompetenzen (SEK-ES). Diagnostica 2013, 59(1):17-32

59. Gratz KL, Roemer L: Multidimensional assessment of emotion regulation and dysregulation: Development, factor structure, and initial validation of the Difficulties in Emotion Regulation Scale. J Psychopathol Behv 2004 26(1):41-54

60. Backenstrass M, Pfeiffer N, Schwarz T, Catanzaro SJ, Mearns J: Reliabilität und Validität der deutschsprachigen Version der Generalized Expectancies for Negative Mood Regulation (NMR) Scale. Diagnostica 2008, 54(1):43-51.

61. Otto JH, Döring-Seipel E, Grebe E, Lantermann E-D: Entwicklung eines Fragebogens zur Erfassung der wahrgenommenen emotionalen Intelligenz. Diagnostica 2001, 47(4):178-187.

62. Schwarzer R, Jerusalem M: Skalen zur Erfassung von Lehrer- und Schülermerkmalen. Dokumentation der psychometrischen Verfahren im Rahmen der Wissenschaftlichen Begleitung des Modellversuchs Selbstwirksame Schulen. Berlin: Freie Universität Berlin; 1999.

63. Altstötter-Gleich C, Bergemann N: Testgüte einer deutschsprachigen Version der mehrdimensionalen Perfektionismus Skala von Frost, Marten, Lahart und Rosenblate (MPS-F). Diagnostica 2006, 52(3):105-118. 
64. Collani G, Herzberg PY: Eine revidierte Fassung der deutschsprachigen Skala zum Selbstwertgefühl von Rosenberg. Zeitschrift für Differentielle und Diagnostische Psychologie 2003, 24(1):3-7.

65. Velten E: A laboratory task for the induction of mood states. Behav ResTher 1968, 6:473-482.

66. Staufenbiel SM, Penninx BW, Spijker AT, Elzinga BM, van Rossum EF: Hair cortisol, stress exposure, and mental health in humans: a systematic review. Psychoneuroendocrinology 2013, 38(8):1220-1235.

67. Ahn C, Overall JE, Tonidandel S: Sample size and power calculations in repeated measurement analysis. Comput Methods Programs Biomed 2001, 64(2):121-124.

68. Krull JL, MacKinnon DP: Multilevel modeling of individual and group level mediated effects. Multivar Behav Res 2001, 36(2):249-277.

69. Preacher KJ, Rucker DD, Heyes AF: Addressing moderated mediation hypotheses: theory, methods, and prescriptions. Multivar Behav Res 2007, 42(1):185-227.

70. McArdle JJ: Latent variable modeling of differences and changes with longitudinal data. Annu Rev Psychol 2009, 60:577-605.

doi:10.1186/1471-244X-14-20

Cite this article as: Ehret et al.: Reducing symptoms of major depressive

disorder through a systematic training of general emotion regulation

skills: protocol of a randomized controlled trial. BMC Psychiatry

2014 14:20.

\section{Submit your next manuscript to BioMed Central and take full advantage of:}

- Convenient online submission

- Thorough peer review

- No space constraints or color figure charges

- Immediate publication on acceptance

- Inclusion in PubMed, CAS, Scopus and Google Scholar

- Research which is freely available for redistribution 